\title{
An Unusual Presentation of Dermatophytid Reaction
}

\author{
Ziani J*, Douhi Z, Bennani M, Elloudi S, Baybay H and Mernissi FZ
}

Department of Dermatology, Hassan II hospital university, Fez, Morocco

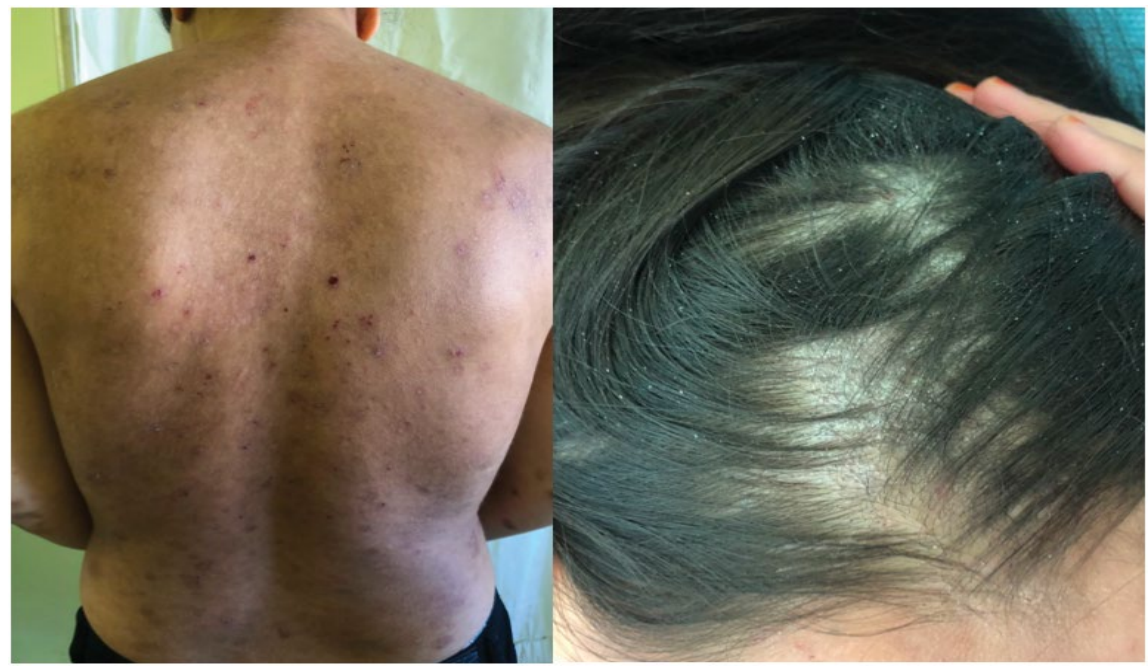

Figure 1: Dermatophytid reaction.

\section{Clinical Image}

A 20-year-old woman with a history of contact with animals. She has had a rash for 2 years. Clinical examination revealed an eruption of non-follicular papules and micropustules from the trunk and upper limbs, on the scalp of alopecic plaques with floury dander and a sign of positive traction. The rest of the examination showed cervical lymphadenopathy with no other abnormalities. The applied dermocorticoid and the administered griseofulvin are taken at a dose of $20 \mathrm{mg} / \mathrm{kg} /$ day for eight weeks. Dermatophytides are type IV delayed hypersensitivity reactions, secondary to opsonization, by antibodies directed against dermophyte antigens released at the site of infection. They occur in the acute phase of an infection between the 10th and 15th day or after 13 days of introduction of an antifungal treatment [1-3]. Several clinical pictures have been reported and the etiologies are diverse. Clinically, they manifest as rashes, itching [4-6]. The combination of oral corticosteroid therapy with antifungal therapy in the management of inflammatory ringworm is controversial and very little studied, the doses are from $0.5 \mathrm{mg} / \mathrm{kg} / \mathrm{day}$ to $1 \mathrm{mg} / \mathrm{kg} /$ day of prednisone $[7,8]$. Clinical improvement with regression of lesions has been favored by dermocorticoids. It is important to know this clinical presentation in order to adopt the best therapeutic strategy (Figure 1).

\section{Conflicts of Interest}

Author declares that there is no conflict of interest.

\section{References}

1. Grappel, Sarah F, CT Bishop and F Blank. "Immunology of Dermatophytes and Dermatophytosis". Bacteriol Rev 38 (1974): 222-250.

2. Cheng, Nancy, Wright D Rucker and Bernard A. Cohen. "Dermatophytid in Tinea Capitis: Rarely Reported Common Phenomenon with Clinical Implications". Pediatrics 128 (2011): e453-e457.

3. Soria X, V Sanmartín, RM Martí and M Baradad, et al. "Erythema nodosum associated with inflammatory tinea capitis (kerion celsi)". Actas Dermosifiliogr 99 (2008): 319-321.

4. Veien, Niels $\mathrm{K}$, Thais Hattel and Grete Laurberg. "Plantar Trichophyton rubrum infections may cause dermatophytids on the hands". Acta Derm Venereol 74 (1994): 403-404.

5. Al-Aboud, Khalid, Khalid Al-Hawsawi and Abdullah Alfadley. "Tinea incognito on the hand causing a facial dermatophytid reaction". Acta Derm Venereol 83 (2003): 59

6. Romano, Clara, P Rubegni, A Ghilardi and M Fimiani. "A case of bullous tinea pedis with dermatophytid reaction caused by Trichophyton violaceum". Mycoses 49 (2006): 249-250.

7. De las, Heras C, J Borbujo, A Pizarro and M Casado. "Erythema nodosum caused by kerion of the scalp". Clin Exp Dermatol 15 (1990): 317-318.

8. Castriota, Marina, Francesco Ricci, Andrea Paradisi and Barbara Fossati, et al. "Erythema nodosum induced by kerion celsi of the scalp in a child: A case report and mini-review of literature". Mycoses 56 (2013): 200-203.

How to cite this article: Ziani J, Douhi Z, Bennani M and Elloudi S, et al. "An Unusual Presentation of Dermatophytid Reaction". J Mol Genet Med 14 (2020): 445 doi: $10.37421 /$ jmgm.2020.14.445 